Notas técnicas y científicas

\title{
DOMINICAN REPUBLIC (HISPAÑIOLA ISLAND, NORTH-EASTERN CARIBBEAN): \\ A MAP OF MORPHO-STRUCTURAL UNITS AT A SCALE 1:500.000 THROUGH LANDSAT TM IMAGE INTERPRETATION
}

\author{
Sergio Chiesa $^{1)}$ \& Guido Mazzoleni ${ }^{2)}$ \\ 1) CNR - Centro di Studio per la Geodinamica Alpina e Quaternaria, Milano, Italia. \\ E-mail: cnrbg@uninetcom.it \\ 2) GEOISA INTERNACIONAL S.A. - San José, Costa Rica. \\ E-mail: geos@infoweb.co.cr
}

The territory of the Dominican Republic is located in the north-eastern Caribbean and encloses the active plate margin between the North-American and Caribbean plates. According to the literature, this is a complex margin, and in the area of interest it is mainly of the transform type. It is formed by a few microplates, Gonâve to the west and HispañiolaPuerto Rico to the east. This situation is the cause of the high seismicity of the area, with catastrophic earthquake occurrences both in historical and recent times. As a consequence, the purpose of this work is to achieve a better knowledge of the characteristics of the territory, which has also a high population density, and on the definition of the geological risk in general and of the seismic risk in particular.

With the aim of implementing an instrumental network for monitoring the microseisimicity of the whole territory of the Dominican Republic, the geological data available in the literature was collected and synthesised, and a remote sensing study was performed. The latter produced results that agreed well with the general framework described by different authors and confirmed some of their details; in addition, it highlighted some new elements.

The two maps produced, a map of lineaments and a map of morpho-structural units, were based on georeferenced images at a scale $1: 250.000$ (with the exception of the southernmost part of the area studied), with the final map scale being 1: 500.000. The morphostructural map is presented here (Fig.1).

The morpho-structural units were distinguished according to the general morphological characteristics of the territory, such as the shape and relief energy of the landscape, the drainage network pattern, and the magnitude, type and distribution of the deformation. The possible location of the morpho-structural units within transitional areas was also considered. These morphological 
features are clearly controlled by the recent tectonic activity. The activity is the result of an active stress field and consequently shows very recent deformation clearly evident in the satellite images. The main morpho-structural units that were distinguished are the following (see also the extended legend).

1) Quaternary deposits

2) Cordillera Septentrional and Península de Samaná

3) "Lowlands" belt, which includes Cibao and Vega Real valleys

4) Cordillera Central and transition to other units (mainly 5 and 8)

5) Hetherogeneous set of relief units and "lowlands", located between the Cordillera Central and the Península Meridional

6) "Lowlands" belt, which includes the Hoya de Enriquillo

7) Península Meridional and its southernmost relief (the latter partially correspondent to unit 10, in the literature Beata Ridge)

8) Península Oriental

These main units were additionally subdivided into sub-units according to the extended legend. These units show an excellent agreement with the "morpho-tectonic zones" proposed by Lewis (1980) and Lewis \& Draper (1990). For this reason and for facilitating the comparison, the numbers that identify the units were kept the same as those used by the quoted authors, with the exception of unit 1 . This unit corresponds in the literature to the Old Bahama Trench, whilst in the present map, which considers only the dry land portion of the Dominican Republic, it unifies all the quaternary deposits.

The comparison between the units described above and the units defined as Tectonic Terranes in Mann et al. (1995) is less straightforward. These units are defined according to composite field criteria, both petrographic and stratigraphic, which generally do not affect the characteristics that are observable through the remote sensing techniques. The greatest differences are detected in the proximity of fault zones, which are interrupted or deflected. From the satellite images these fault zones appear to continue beyond the interruption points, in the form of swarms of closely spaced lineaments, generally straighter and more persistent than those described in the literature.

An example of this situation is given by the area of the Hispañiola Fault Zone (Fig. 2), where the Tectonic Terranes called TortueMaimon-Amina and Loma Caribe-Tavera are located to the east of the deflection close to $\mathrm{La}$ Vega. The map of lineaments highlights a swarm that stretches the eastern edge of the EnriquilloPlantain Garden Fault Zone towards the east. An even more evident swarm, oriented about $\mathrm{N} 70^{\circ} \mathrm{W}$, adjoins the western portion of the Hispañiola Fault Zone, with the same orientation, close to the previously mentioned deflection. To the west this swarm follows the lower Camú river to the Bahía de Samaná and it seems to extend as far as the Laguna del Limón. This swarm of lineaments appears to be linked to an important tectonic element and, consequently, it contributes to the peculiar morphological characteristics of the whole Península Oriental, which are greatly different from the rest of the studied area.

The Península Oriental (unit 8) is a separated physiographic element, with little deformation present, being mostly of the shear type, as no clear evidence of thrusting was observed. According to the characteristics of the drainage network and to the superficial deposits, this area appears to be affected by a slight, progressive and homogeneous tectonic uplift. This type of uplift is completely different from the much more rapid one that characterises the western sectors of the studied area, identified by sequences of mountain ridges and tectonic valleys. The Península Oriental is a portion of the microplate called Hispañiola- Puerto Rico in the literature (with reference to the structural scheme).

This area is located at some distance from Hispañiola-Puerto Rico microplate's western margin; this margin is greately influenced by the intense deformation and the marked uplift of the 


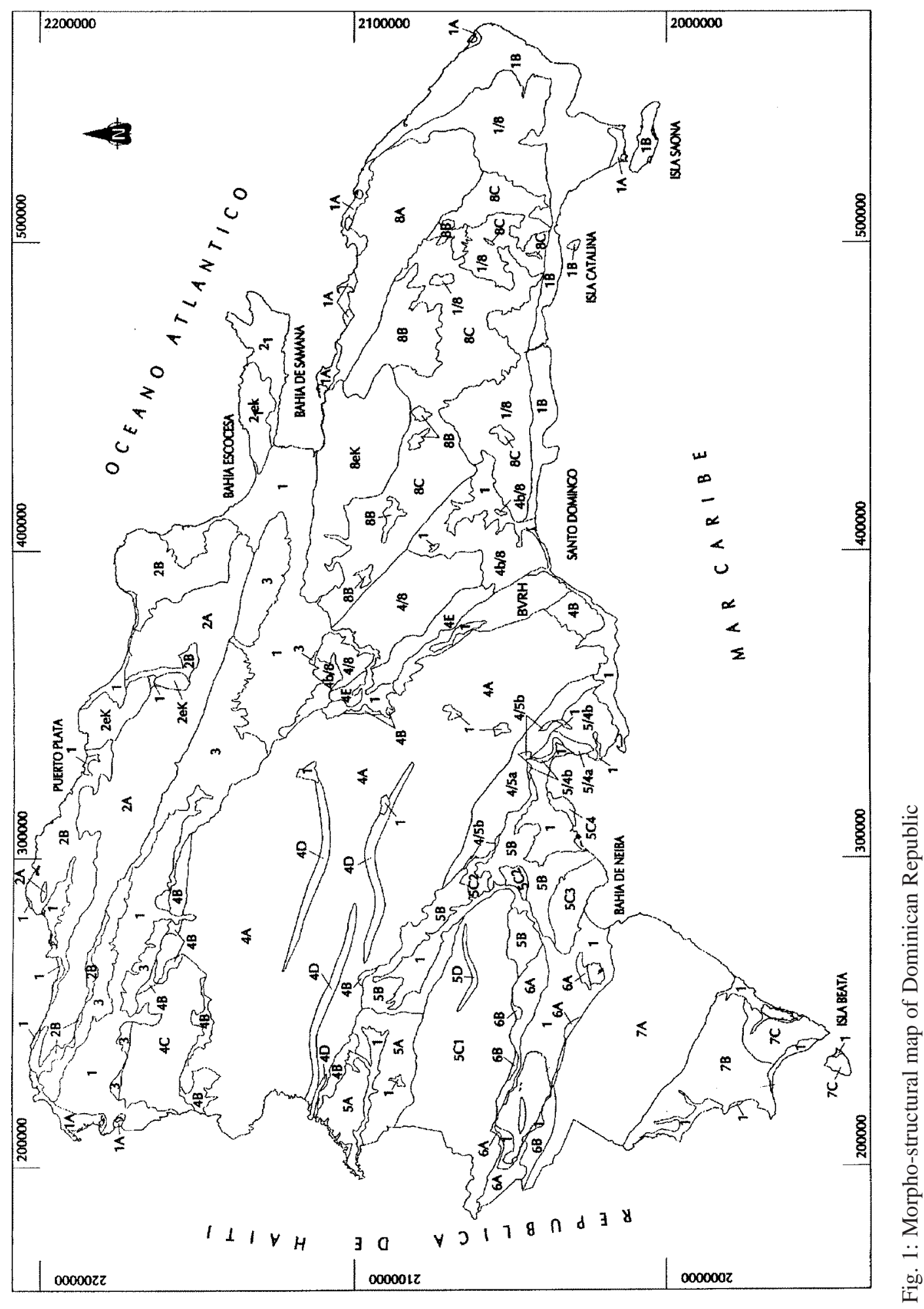




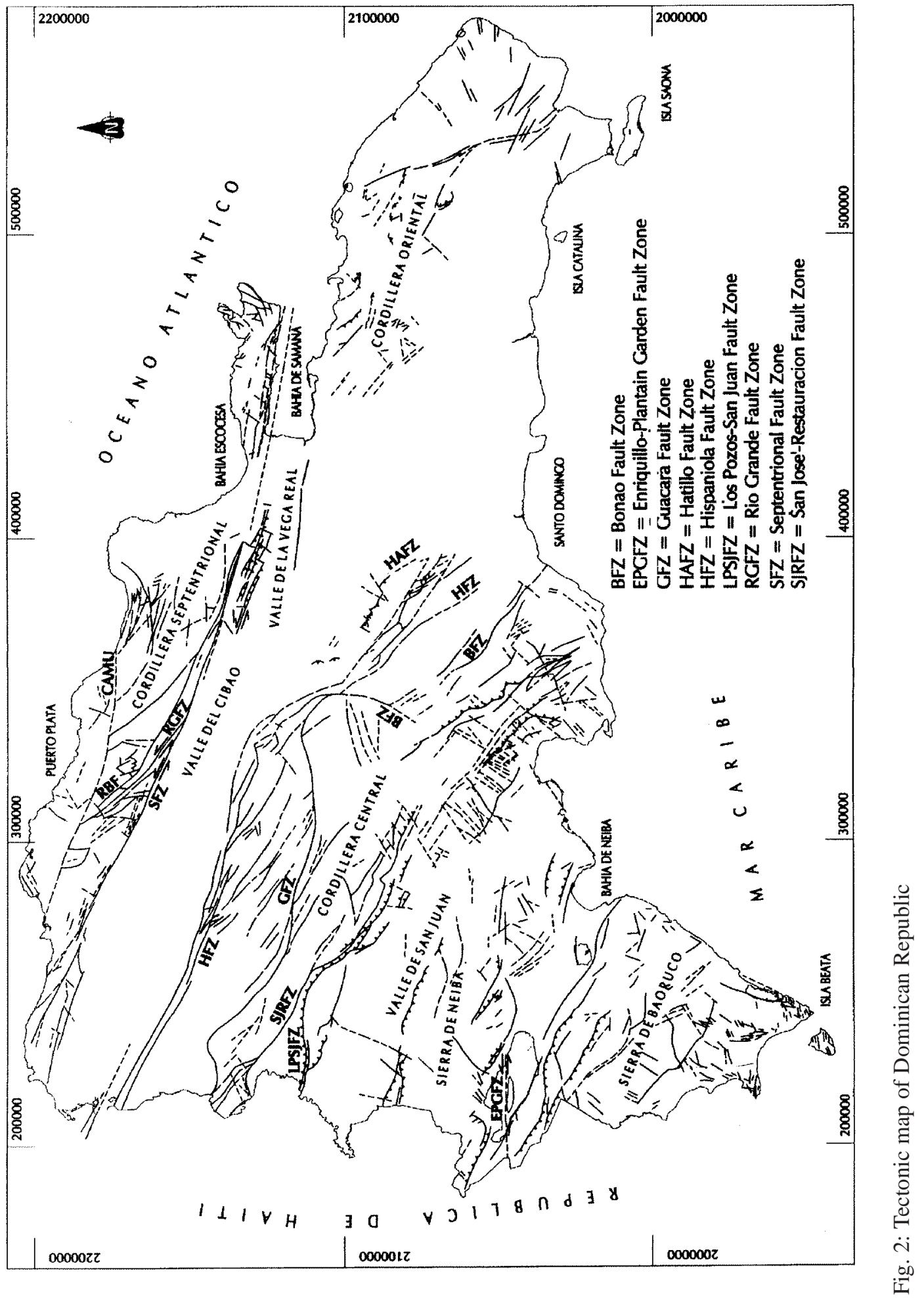


nearby Cordillera Central mountain range, located to the west of the plate margin. This is the reason the Península Oriental is relatively less deformed. In the literature the peninsula is considered an area with minimal or null uplift when compared to the areas to the west, which are an important structural boundary. This boundary, striking $\mathrm{N}-\mathrm{S}$ and located $71^{\circ} \mathrm{W}$ longitude according to Skyes et al. (1982) or $70^{\circ} \mathrm{W}$ longitude according to Mann et al. (1995), separates areas with different characteristics, as for example the depth of the earthquakes' focuses. As far as this structural boundary is concerned, the present study showed the presence of a characteristic intensely deformed strip, oriented about N-S, and stretching from Boca de Yásica to the north to the lower Río Ocoa to the south, corresponding to the structural boundary. This position is in between the two locations referenced above, slightly closer to the one at a longitude of $70^{\circ} \mathrm{W}$. In the proximity of the observed strip, in addition to the already known marked torsion of the Bonao Fault Zone, the N-S lineaments have their greatest concentration, and Quaternary deposits, apparently filling "intermountain basins". The Península Oriental appears generally massive and "old", could be interpreted as a meseta surface with modest mountain ranges located at its margins. The highest relief, the Cordillera Oriental slightly over $700 \mathrm{~m}$ a.s.l., is the less defined physiographic element.

The Cordillera Central (unit 4), as mentioned above, is the margin zone between the microplates known in the literature as Gonâve and Hispañiola-Puerto Rico. It forms the central mountain range of the whole Hispañiola island, including its culmination, the Pico Duarte. The Cordillera Central is a wide belt of harsh relief, with elevations over $3.000 \mathrm{~m}$ a.s.1., bounded to the north and to the south by two important "lowland" strips of clear tectonic origin, roughly oriented WNW-ESE. These are the Cibao valley, that continues to the east to Bahía de Samaná in the Vega Real valley, and the system Río Macasía-San Juan valleys. The very "young" appearance of the Cordillera Central, evidenced by widespread slope instability phenomena on the steep mountainsides and by the deeply cut drainage network, encompasses the morphological characteristics of an area affected by a rapid and marked uplift. By contrast, the adjacent tectonic valleys appear to be completely different as they are affected by strong subsidence. The general orientation of the Cordillera Central is basically parallel to the orientation of the main tectonic elements that cross or border it. In spite of its general massive appearance the Cordillera Central is affected by minor topographic "accidents" of clear tectonic origin. Among these the "linked-arc" shapes described as unit 4D are particularly representative. These are both deeply eroded trenches and bands, with a curvilinear shape and distributed along structurally controlled alignments. They can affect the water divides of adjacent valleys and favour possible river capture phenomena. In more detail, they are formed by highly fractured rock bands, linked to fold axial planes or fault zones. Moreover, two systems of morphological steps were noticed. They are linked to normal faulting and are oriented approximately WNW-ESE, towards the Cibao valley and mainly along the Hispañiola Fault Zone, and about $\mathrm{N} 60^{\circ} \mathrm{E}$, in the central-eastern portion of the Cordillera Central, in a sector bounded by the Las Cuevas and the Yuna rivers. In the latter area the products of a Pliopleistocenic volcanism were observed. The junction between the Cordillera Central and the Península Meridional occurs through the most complex and composite sector in the whole area studied. In this sector most of the transitional units identified are present (see legend). In particular, the units 4E, BVRH, and to a lesser extent 4b/8, show clear indications of deformation, most likely caused by extension/transtension stresses. This is evidenced by the NW-SE oriented morphological steps related to normal faults, semi-graben and possibly complete horst/graben structures, which can be observed in the Río Haina valley area.

The Península Meridional (unit 7) shows some aspects that partly recall the Península Oriental, although it is evidently more deformed, being affected by both transtensive and thrusting 
phenomena at its northern border. The "skeleton" of the Península Meridional is formed by the set of mountains that culminate with the Sierra de Baoruco, with elevations of over $2.000 \mathrm{~m}$ a.s.l. It was possible to observe ridges, trenches, and general morphology mainly oriented $\mathrm{N} 50^{\circ} \mathrm{W}$, parallel and sub-parallel to extensive or transtensive structures, oriented $\mathrm{N} 40^{\circ} \mathrm{W}$, such as morphological steps, normal faults, and proper grabens. For example one graben can clearly be observed near Pelempito. The presence of extensive/transtensive structures that are parallel or sub-parallel to the morphological axis of a sierra or mountain ridge represents an interesting aspect. This situation can be related to the deformation that affects the surface part of a tectonic structure. In the southernmost part of this unit, which is separated from the more massive part by an uncertain curvilinear morphological limit, a set of discontinuous and irregularly distributed small ridges was observed. They are aligned along a rough N-S direction and are affected by topographical "accidents", mainly oriented NNE-SSW. These ridges are parallel to the southernmost coastline, between Cabo Beata and the southern edge of the Bahía de Neiba. They are extensive/transtensive structures of minor importance, and they are clearly cut by the NW-SE oriented set of structures. It has to pointed out that this stretch of coastline is effectively straight, sharply cutting the ridges, and the ridges have high elevations close to the coast. In general, the Península Meridional is fairly massive and asymmetric. The north-facing mountain slopes, towards the tectonic valley of the Hoya de Enriquillo, are steeper than the south-facing slopes, towards the Canal de la Beata, which are smoother and probably covered by superficial deposits and hence more regular. Only small incisions are present, caused by transversal topographic "accidents", such as minor valleys with orientation ranging from NE-SW to NNW-SSE. These are discontinuous and much less evident than the NW-SE oriented grabens. Moving towards the coast it is possible to notice a change of inclination of the slope, which is evident although partially levelled by the superficial deposits, and a sharp uplifted step that culminates with the Punta del Cerro.

There are other areas constituted by mountain ranges that are important, besides the complex and heterogeneous set that was grouped under unit 5. The ones that show particular characteristics are those located at the northern border of the area studied (unit 2). Here, two different physiographic elements are present: the Cordillera Septentrional and the Península de Samaná. The former is a rather narrow and asymmetric strip with elevations at around 1.000 $\mathrm{m}$ a.s.1., has strong morphological relief energy, and is oriented WNW-ESE. To the south, towards Cibao valley, it is sharply interrupted by a clearly evident boundary, which is probably both the most important tectonic element and a seismic source, the Septentrional Fault Zone. The Península de Samaná, which has less surface area, is formed by a set of more modest and apparently "older" mountain ridges, with maximum elevations at around $500 \mathrm{~m}$ a.s.l. It is described in the literature as an allochthonous physiographic element, of eastern provenance, which was pasted to the greatest mass of Hispañiola island by accretion processes, through migration towards the west along a sinistral strike-slip fault, part of the Septentrional Fault Zone.

Beyond the physiographic elements of the mountain ranges described so far, the territory studied is also constituted of related relevant extensions of "lowlands". These form the structural limits of the mountain ranges and show that the tectonic uplift of Hispañiola island is markedly differential, when compared to the slight and homogeneous one hypotised for the Península Oriental. It is worth noting that geophysical surveys have shown that the depth of the bedrock underneath the recent sedimentary prisms that constitute the filling of the valleys in the "lowlands" is below sea level. From north to south the first "lowland" strip encloses the Cibao and Vega Real valleys (unit 3). In the study area this strip extends continuously for about $240 \mathrm{~km}$ from the Bahía de Manzanillo to the west, to the Bahía de Samaná to the east, with general orientation WNW-ESE (about $\mathrm{N} 70^{\circ} \mathrm{W}$ in the 
western sector, $\mathrm{N} 60^{\circ} \mathrm{W}$ in the central sector, and $\mathrm{N} 75^{\circ} \mathrm{W}$ in the eastern sector). In the axial part, the highest elevations, slightly less than $200 \mathrm{~m}$ a.s.l., can be observed in the central sector where, to the east of the town of Santiago, the low water divide between Río Yaque and Río Yuna is located. The Vega Real and Cibao valleys are bounded or crossed by a closely spaced set of morphological steps, which are increasingly more evident from west to east. For simplicity, the steps coinciding with the limits between unit 3 and the adjacent units were not drawn on the map of morpho-structural units, but they can very clearly be seen in the map of lineaments.

Further south, wedged between the Sierra de Neiba (unit 5) to the north and the massive Sierra de Baoruco (unit 7) to the south, the second most important "lowlands" strip, unit 6 , is located. In the study area this unit is represented by the depression of the Hoya de Enriquillo, with topographic elevations below sea level. However, this "lowlands" strip is part of a greater motif that crosses the whole Hispañiola island, following the west side of the EnriquilloPlantain Garden Fault Zone. The eastern portion of unit 6 appears to be more greatly affected by the extensional tectonics. Particularly interesting and characteristics is the Laguna de Rincón sector. Here the geometry of the observed steps seems to recall a transtensive basin, probably of the pull-apart type. This is particularly evident at the northern rim of the Laguna, where the small ridges present are sharply truncated, and less clear at the southern rim. This seems to be partially due to the objective fact that the image is disturbed by the presence of clouds that are always particularly dense along the whole southern edge of the Hoya de Enriquillo up to the Bahía de Neiba, and partially to the lesser continuity and length of the tectonic elements that here appear more segmented.

\section{REFERENCES}

LEWIS, J.F., 1980: Resumé of the geology of Hispañiola. Field guide to the 9th Caribbean Geological Conference, Santo Domingo, Dominican Republic: 5-31.
LEWIS, J.F. \& DRAPER, G., 1990: Geology and tectonic evolution of the northern Caribbean margin. - In: DENGO, G. \& CASE, J.E. (eds.): The caribbean region, The Geology of North America, v. H.: 77140, Geol. Soc. America, Boulder, Colorado.

MANN, P., TAYLOR, F.W., EDWARDS, R.L. \& KU-TEHLUNG, 1995: Actively evolving microplate formation by oblique collision and sideways motion along strike-slip faults: en example from the northeastern Caribbean Plate margin. Tectonophysics, 246 (1-3): 1-69.

SYKES, L.R., McCANN, W.R. \& KAFKA, A.L., 1982: Motion of Caribbean plate during last 7 million years and implications for earlier Cenozoic movements. - J. Geoph. Res. 87: 10656-10676.

\section{EXTENDED LEGEND}

\section{Quaternary deposits}

1) Recent alluvial deposits - coastal plain deposits, undifferentiated.

1A) Coastal swamp deposits, with presence of water at the surface.

1B) Coastal deposits of the Península Oriental.

1/8) Undifferentiated quaternary deposits, generally discontinuous covers of modest thickness, laying on the meseta of the Península Oriental.

\section{Cordillera Septentrional and Península}

de Samaná Units

2A) Properly called Cordillera, with high morphological relief energy.

2B) Lower relief energy terrains, morphologically belonging to the Cordillera Septentrional (locally narrow transitional strips to flatter adjacent areas)

2ek) Areas with strong chemical erosion (karst lapies)

$\left.2^{1}\right)$ Península de Samaná

$2^{1} \mathrm{ek}$ ) as 2ek) Involving carbonate rocks of the Península de Samaná.

Valle del Cibao Units

3) "Lowlands" of the Cibao and Vega Real valleys.

\section{Cordillera Central Units}

4A) Properly called Cordillera, with high morphological relief energy.

4B) Transition to flatter adjacent areas. Moderate relief energy, probably related to the presence of discontinuous colluvial covers.

4C) Transition, with gradual boundary to units 1 and 3 . Minimal relief energy, probably related to the presence of extensive colluvial covers.

4D) Alignment of linked-arc shapes (e.g. Rincón Grande Arroyo los Golfitos). These shapes are probably linked to fold axial planes, intensely fractured bands, and/or fault zones. 
4/5a) Cordillera Central, transition to the coastal ranges of the Bahía de Ocoa. High relief energy.

4/5b) Same as previous, low relief energy.

BVRH) "Lowlands" alignment Bonao - Valle del Río Haina. Morphological boundary of the properly called Cordillera Central, with apparent general graben features. Transition to units 8 .

4E) Area to the east of the Río Haina valley, affected by longitudinal steps, with the same NW-SE orientation of the valley (partial horst). Sharp passage to unit 4/8.

4/8) Transition to the meseta of the Península Oriental, strong/medium relief energy.

4b/8) Same as previous, moderate relief energy.

Heterogeneous set of relief and "lowland" units, between the Cordillera Central and the Península Meridional

5A) Río Macasia valley. Slightly irregular valley plain, due to the presence of isolated hills.

5B) San Juan valley. Fairly regular valley plain, especially in its northern part.

5C1)Sierra de Neiba.

5C2) Ridges adjacent to the Sierra de Neiba, to the east of Río San Juan.

5C3) Sierra de Martín García.

5C4) Coastal ridges of the Bahía de Ocoa. 5/4a) Transition to the Cordillera Central, medium relief energy.

5/4b) Same as previous, low relief energy.

5D) Alignment of linked-arc shapes (see unit 4D), affecting the ridges of the Sierra de Neiba.

Units belonging to Gonâve Island -

Hoya de Enriquillo "lowlands" belt

6A) Proper "Lowlands", minimal relief energy.

6B) Set predominantly composed of "lowlands" and subordinate small relief (transition to unit 7A).

Península Meridional Units

7A) Properly called Península Meridional.

7B) Transition to the Canal de la Beata.

7C) Southernmost ridges, Isla Beata.

\section{Península Oriental Units}

8A) Cordillera Oriental, high/medium relief energy.

8B) Meseta de Seibo, "rising" ridges.

8C) Properly called Meseta de Seibo, the surface is flattened by thin and discontinuous superficial deposits. Apparently affected by strong stream erosion, differently from unit $1 / 8$.

8ek) Areas with strong chemical erosion (see unit 2ek) affecting carbonate rocks of the Meseta de Seibo. 